\title{
A STUDY OF THE SCHOLARLY PUBLICATION REVIEW PROCESS
}

\author{
Nancy L. Denton, Sarah E. Leach \\ Purdue University
}

$\underline{\text { Abstract }}$

Publication of reviewed or refereed articles is a common method of disseminating scholarly work. This paper explores the review processes in place for American Society for Engineering Education (ASEE) publications, including conference proceedings, papers, journal articles, and Prism magazine. The effect of the peer review process on conference proceedings papers is considered, and suggestions for future actions to strengthen the process are included.

$\underline{\text { Introduction }}$

Historically, the ASEE Annual Conference offered a venue for faculty to discuss their thoughts, opinions, and efforts toward improving engineering education in an open environment. Some papers were reviewed, others were published based on the content of their abstracts, and still others appeared as abstracts only, with copies of the paper hand-distributed at the conference. This variation in approaches led to concern that ASEE conference proceedings papers were viewed as having little scholarly value by academic institutions, and perhaps served as a core reason for the drop in ASEE membership by faculty at many engineering research universities. In the early 1990s, the leadership of ASEE adopted a policy that all of its divisions would establish a formal paper review process. By the late1990s, the publication process was streamlined so that all manuscript submissions met one consistent deadline for consideration for publication. The process has continued to be refined as ASEE introduced and revised the CAPS automated paper submission process so that currently, all abstracts and manuscripts are reviewed, and final paper acceptance requires program chair approval. These changes to the paper review process coincided with national efforts to enhance the level and acceptance of engineering education as a field of scholarship. Other evidence of the growth of engineering education as a discipline include significant funding from the National Science Foundation (engineering education coalitions, advanced technology education centers) and organizations such as the Society of Manufacturing Engineers, the reinstatement and growth of ASEE's Journal of Engineering Education and the development of several new engineering education journals (International Journal of Engineering Education, International Journal of Modern Engineering, the Journal of Science, Technology, Engineering and Mathematics Education), and the recent establishment of departments of engineering education at Carnegie I Research universities (e.g., Purdue University and Virginia Polytechnic Institute and State University). ${ }^{1-7}$

A key factor in developing the current peer review process for ASEE conference proceedings papers was the belief that the papers were not perceived to be at a high level of scholarship. A 
meaningful record of scholarly publications is valuable not only to individual faculty members, but is increasingly also used by institutions as a measure of program performance. ${ }^{8-10}$ To see if the peer review process has succeeded in elevating the perception of scholarship quality, a survey of current ASEE division chairs was conducted. In addition, the survey attempted to shed light on how each division has implemented its review process. The multiple-choice survey was distributed to forty-seven (47) ASEE Division Chairs via e-mail. Twenty-one (21) responses were received. The twenty-one responding divisions represent $53 \%$ of the papers published in the 2004 ASEE Annual Conference Proceedings.

Table 1: Peer Review Survey Results

\begin{tabular}{|c|c|}
\hline $\begin{array}{c}\text { Percentage } \\
\text { of } \\
\text { responses }\end{array}$ & Survey questions and possible responses \\
\hline & $\begin{array}{l}\text { 1. Does your division use a masked review process (keep the author(s) identity } \\
\text { hidden from the reviewers)? }\end{array}$ \\
\hline $62 \%$ & Yes \\
\hline $38 \%$ & No \\
\hline & 2. The author(s) can identify their peer reviewers \\
\hline $100 \%$ & $\begin{array}{l}\text { a. only if the peer reviewers choose to contact the author(s) outside the } \\
\text { process }\end{array}$ \\
\hline & $\begin{array}{l}\text { b. by checking other division documentation/postings/correspondence not } \\
\text { intended for authors }\end{array}$ \\
\hline & c. easily. There is little or no attempt to conceal the identity of peer reviewers. \\
\hline & 3. The author(s) can link peer reviewers' comments to individual peer reviewers \\
\hline $100 \%$ & $\begin{array}{l}\text { a. only if the peer reviewers choose to contact the authors(s) outside the } \\
\text { process }\end{array}$ \\
\hline & $\begin{array}{l}\text { b. by checking other division documentation/postings/correspondence not } \\
\text { intended for authors }\end{array}$ \\
\hline & c. easily. There is little or no attempt to conceal the opinions of peer reviewers \\
\hline & 4. The review criteria used by your division \\
\hline $24 \%$ & a. is identical to the ASEE Best Paper selection criteria \\
\hline $10 \%$ & b. supplements the ASEE Best Paper selection criteria \\
\hline $28 \%$ & c. replaces the ASEE Best Paper selection criteria \\
\hline $28 \%$ & d. is left to the discretion of the peer reviewer \\
\hline $10 \%$ & e. other \\
\hline & 5. How does your division recruit its peer reviewers? \\
\hline $52 \%$ & a. issues a call for volunteers \\
\hline $10 \%$ & b. review committee(s) \\
\hline $5 \%$ & c. session moderator solicits/identifies his/her reviewers \\
\hline $76 \%$ & d. program chair solicits/identifies his/her reviewers \\
\hline
\end{tabular}




\begin{tabular}{|c|c|}
\hline $24 \%$ & e. other \\
\hline & $\begin{array}{c}\text { 6. Based on your experience with ASEE, the peer review process has impacted the } \\
\text { scholarly aspects of the Annual Conference Proceedings }\end{array}$ \\
\hline $24 \%$ & $\begin{array}{l}\text { a. by substantially raising the quality of the writing } \\
\text { b. by raising the quality of the writing somewhat }\end{array}$ \\
\hline $57 \%$ & c. in no significant way \\
\hline $10 \%$ & d. in a negative way. (Explain \\
\hline & $\begin{array}{c}\text { 7. At your institution, how do you feel ASEE Conference Proceedings papers are } \\
\text { perceived, with respect to their role in scholarly endeavor? }\end{array}$ \\
\hline $5 \%$ & $\begin{array}{c}\text { a. conference proceedings papers do not imply scholarship, especially not } \\
\text { ASEE proceedings papers }\end{array}$ \\
\hline $38 \%$ & $\begin{array}{c}\text { b. all conference proceedings papers have a minor role in scholarship, } \\
\text { including ASEE's proceedings papers }\end{array}$ \\
\hline $14 \%$ & $\begin{array}{c}\text { c. ASEE proceedings papers are valued more than some other proceedings } \\
\text { due to their educational content }\end{array}$ \\
\hline $38 \%$ & d. all publications indicate scholarly endeavor \\
\hline $14 \%$ & e. other \\
\hline & $\begin{array}{c}\text { 8. If your division publishes a division journal, please provide the journal name } \\
\text { plus the name and contact information for its editor. }\end{array}$ \\
\hline Two responses received \\
\hline
\end{tabular}

$\underline{\text { Comments and observations on survey results }}$

Question 1: It is the authors' impression that most academic institutions value masked review processes more highly than open reviews. The possibility of reviewer bias based on the identity of the author exists whenever the author is known. Although peer reviewers strive to remain objective, eliminating the possibility of bias will strengthen the peer review process, as appears to be supported by over $60 \%$ of the responding divisions. Consistent with this perception, the Journal of Engineering Technology's editorial board transitioned from blind to double-blind, or masked peer reviews, as indicated by revised manuscript submission information first disseminated in the Spring 1999 issue. $^{12}$

Questions 2 and 3 are directly related, so comments will be combined. All responses indicate that division chairs believe their divisions conduct blind reviews, where the reviewers' identity is well-hidden from the authors. In practice, we have found that the review process is relatively transparent in several divisions. While the reviewer comments cannot easily be linked to a specific reviewer, the author can frequently identify the handful of reviewers for a given session or subject within a division. Divisions may wish to reconsider how they handle correspondence to reviewers (who are also often authors within the same division) to make the review process, particularly the identity of reviewers, more opaque. Responses to question 5 suggest that most peer reviewers are selected through a voluntary solicitation process. It is possible that additional 
screening is warranted, to ensure reviewers for a division who are also authors within that same division do not have access to information about the full reviewer/author pool.

Question 4 indicates that over one quarter of the ASEE divisions leave paper reviewing to the discretion of the reviewer, while more than half do not follow the ASEE Best Paper criteria at all. If raising the quality and perception of the value of ASEE conference proceedings papers is an objective of the ASEE leadership, establishing minimum review criteria for all ASEE papers should be considered.

Raising the quality of ASEE conference proceedings papers and their acceptance within the academic community as a venue for sharing scholarly endeavor appear to be positive results of the peer review process. Other possible reasons for the enhanced view of ASEE proceedings paper quality may be tied to the elevation of engineering educational scholarship as a discipline or as an outgrowth of interdisciplinary educational collaborations. The responses to questions 6 and 7 serve as a strong indicator that the peer review process should continue as a critical element in the publication process, even for conference proceedings papers. The role of the peer review process is especially significant to the engineering technology educator, where nearly $70 \%$ of respondents to a mid-1990s survey indicated conference proceedings papers were important or very important evidence of scholarship. ${ }^{13}$

\section{$\underline{\text { Other ASEE Publications }}$}

Articles submitted to the Journal of Engineering Education undergo a peer review, coordinated by one of the journal's Associate Editors. The explanation for submission and review of manuscripts contains no explicit description of a masked review process, but does provide a list of review criteria. ${ }^{3}$

Instructions to potential authors posted on the web pages of the Engineering Design Graphics Journal (EDGJ) and the Computers in Education Journal do not contain any reference to a masked review process. The EDGJ uses an editorial review board. ${ }^{14}$ The review process for the Computers in Education Journal is not described in detail. ${ }^{15}$

Manuscript requirements for the Journal of Engineering Technology include instructions to facilitate masked review, which is standard practice for this journal. Authors are instructed to remove biographical references and identifying information in the text before submitting a manuscript for review. ${ }^{16}$

Prism magazine is an ASEE publication that is intended for dissemination of current items of interest for the engineering education community and others interested in development of the technical workforce. The review process is conducted by the magazine's editorial staff. Following acceptance, manuscripts are subject to significant editing to meet internal requirements such as space limitations. The online Prism WebExtra often lists related and/or expanded articles that undergo a similar staff-based review and editing process. ${ }^{17}$ 


\section{$\underline{\text { Summary }}$}

The number of venues available for publication of engineering and engineering technology educational scholarship has increased significantly during recent years. The establishment of some type of required peer review process for all ASEE Annual Conference Proceedings papers has contributed to the perceived enhancement of their quality and acceptance as a form of scholarly work. Through its technical division journals and the Journal of Engineering Education, ASEE is providing a number of means for archival dissemination of educational scholarship of interest to engineering educators.

\section{$\underline{\text { References }}$}

1. National Science Foundation Division of Undergraduate Education mission, http://www.nsf.gov/ehr/due/about.jsp, retrieved February 28, 2005.

2. Education Committee, Society of Manufacturing Engineers Foundation mission, http://www.sme.org/cgibin/smeefhtml.pl?/foundation/grants/grants.htm\&\&\&SEF\&

3. ASEE Journal of Engineering Education Guide for Authors, http://www.asee.org/about/publications/jee/guide.cfm, retrieved March 1, 2005.

4. International Journal of Engineering Education Notes for Contributors, http://www.ijee.dit.ie/contrib.html, retrieved March 1, 2005.

5. Journal of Industrial Engineering Design, Instruction for Authors, http://cegt301.bradley.edu/ iedasee/jied.inst.html, retrieved March 1, 2005.

6. International Journal of Modern Engineering, About Us, http://www.21centuryengineer.com/, retrieved March 1, 2005.

7. Journal of Science, Technology, Engineering, and Mathematics Education, Values and Mission Statement, http://www.jstem.org/, retrieved March 1, 2005.

8. Johnson K., and Rajai M. (2001). Conquering the hurdles of promotion and tenure for junior faculty members. 2001 ASEE Annual Conference Proceedings.

9. Lozano-Nieto, A. (2002). Integrating teaching, research and service to develop scholarly publications. of the 2002 ASEE Annual Conference Proceedings.

10. Hundley, S.P., Reiman, M., Fox, P.L. and Yurtseven, O. (2004). Charting our course: Strategic planning approaches in Engineering and Technology. 2004 ASEE Annual Conference Proceedings.

11. Publication Manual of the American Psychological Association, Fifth Edition. (2001). American Psychological Association, Washington, D.C.

12. Manuscript requirements. (1999). Journal of Engineering Technology, 16(1), page 33.

13. Buchanan, W. (1996). A survey of creative endeavor criteria for promotion and tenure of ET faculty. Journal of Engineering Technology, Vol. 13, \#1, Spring 1996, pp. 30-36.

14. Author guidelines. ASEE Engineering Design Graphics Journal, http://www.east.asu.edu/edgj/edgj/index.html

15. ASEE Computers in Education Journal, http://www.asee.org/about/publications/divisions/index.cfm\#Computers in_Education_Journal, retrieved March 1, 2005.

"Proceedings of the 2005 American Society for Engineering Education Annual Conference \& Exposition Copyright (C) 2005, American Society for Engineering Education” 
16. Style Guide for Authors, Journal of Engineering Technology, http://www.engtech.org/JET.pdf, retrieved March $1,2005$.

17. Prism Magazine, http://www.asee.org/about/publications/prism/aboutprism.cfm, retrieved March 1, 2005.

\section{Biographical Information}

NANCY L. DENTON, P.E., VS3

Professor and Associate Head of Mechanical Engineering Technology at Purdue University, Prof. Denton teaches in the areas of mechanics and testing, and coordinates accreditation preparation for the MET program. She is active in ASEE and the Vibration Institute.

\section{SARAH E. LEACH}

An Assistant Professor of Mechanical Engineering Technology for Purdue University since 1999 teaching courses in materials, mechanics, and manufacturing processes. Prof. Leach received a B.E. in Mechanical Eng. from Vanderbilt University and an M.S. in Materials Science and Eng. from the University of Notre Dame. She was employed for 15 years by the CTS Corporation in Elkhart, Indiana, working in product and materials development. 